\title{
CONSTRUÇão DE UMA CÉlULA DE GÁS DE BAIXo CUSTO PARA ANÁLISE NO INFRAVERMELHO
}

\author{
Keroly Alaíde Pascoal Colati* e Reginaldo Bezerra dos Santos \\ Departamento de Química, Universidade Federal do Espírito Santo, Av. Fernando Ferrari, 514, 29075-910 Vitória - ES, Brasil \\ Carlos Gilmar Zucolotto Júnior, Evaristo Nunes Filho e Alfredo Gonçalves Cunha \\ Departamento de Física, Universidade Federal do Espírito Santo, Av. Fernando Ferrari, 514, 29075-910 Vitória - ES, Brasil
}

Recebido em 11/6/10; aceito em 13/11/10; publicado na web em 18/2/11

\begin{abstract}
CONSTRUCTION LOW-COST GAS CELL FOR INFRARED ANALYSES. Infrared spectroscopy is a versatile technique used for qualitative and quantitative determination of all types of molecular species. As far as analysis of confined or flowing gases is concerned, different types of cell can be found in the market, but they are often very expensive. This study describes the construction of a very efficient gas cell with good reproducibility for qualitative infrared analysis of confined or flowing gases, using easily available and low-cost materials.
\end{abstract}

Keywords: gas cell; infrared qualitative analyses; FT-IR.

\section{INTRODUÇÃO}

A espectroscopia no infravermelho é, atualmente, uma das mais importantes técnicas analíticas instrumentais empregadas em laboratórios de pesquisas e de controle de qualidade de indústrias farmacêutica, alimentícia, têxtil, petroquímica, etc. ${ }^{1} \mathrm{O}$ uso dos equipamentos de FTIR (infravermelho com transformada de Fourier) tem, nos últimos anos, crescido consideravelmente, sendo de grande utilidade como ferramenta na determinação estrutural de substâncias e na quantificação de um ou vários constituintes em misturas complexas. Este crescimento foi impulsionado pelo fato de que tais equipamentos se tornaram mais acessíveis, tanto economicamente, quanto na rapidez e precisão na aquisição de resultados, assim como na facilidade de operação. Diante disto, tem-se desenvolvido e aprimorado métodos e dispositivos, direcionados tanto a análises qualitativas quanto quantitativas no infravermelho.

Os métodos mais usados para obtenção de espectros no infravermelho são os de transmissão e reflexão. ${ }^{2}$ Para ambos os casos, dependendo do tipo da amostra a ser analisada, sólida, líquida, gasosa, translúcida ou opaca, existem vários acessórios disponíveis comercialmente. A maior parte dos equipamentos de FTIR permite o acoplamento de diferentes tipos de dispositivos para diferentes tipos de análises.

Para as análises no infravermelho de amostras gasosas existem vários modelos de células de gás disponíveis no mercado. As células de gás, de modo geral, podem ser divididas em células de caminho óptico curto, destinadas à análise de amostras concentradas, e células de caminho óptico longo, para analisar elementos traço em amostras. Os valores destas células encontram-se na faixa de US\$300,00 a US\$22.000,00, sendo que a variação nos preços está diretamente ligada à especificidade de cada uma delas. Para ambos os modelos, existe a possibilidade de realização de análises com o gás confinado ou em fluxo. ${ }^{3,4}$

Devido à indisponibilidade de recursos financeiros ou à redução de custos, a adaptação ou construção de aparelhos para uso em laboratórios de química ou em equipamentos, mostra-se uma alternativa bastante viável. ${ }^{5}$

*e-mail: kerolycolati@gmail.com
Neste trabalho descreve-se a construção de uma célula de gás para análises qualitativas no infravermelho. A célula possui caminho óptico curto, é provida de janelas de $\mathrm{KBr}$, pode realizar análises com gases confinados ou em fluxo e foi confeccionada a partir de materiais facilmente acessíveis e de baixo custo.

\section{PARTE EXPERIMENTAL}

\section{Construção da célula de gás}

Todos os materiais utilizados na fabricação da célula de gás e do sistema de mangueiras, para o funcionamento da célula, foram adquiridos no comércio para materiais para construção e, também, foram provenientes de materiais reaproveitados dos Departamentos de Química e Física da UFES.

A célula de gás foi construída a partir de um tarugo sextavado de latão medindo $25 \mathrm{~mm}$ de diâmetro e $140 \mathrm{~mm}$ de comprimento, Figura 1. Nesse tarugo foi feito um furo central para a constituição do caminho óptico. Como janelas e para a contenção do gás, foram usadas pastilhas de $\mathrm{KBr}$, confeccionadas no momento de cada análise. No corpo externo da célula foram feitos três orifícios, dois em suas extremidades, interligados, representados pelos números 1 e 2, Figura 1, por onde é introduzido o gás a ser analisado, e um orifício no centro, número 3 , isolado, que se divide em dois canais percorrendo até a parte exterior das janelas de $\mathrm{KBr}$. No orifício de número 3, foi injetado nitrogênio $\left(\mathrm{N}_{2}\right)$, com a finalidade principal de proteger as janelas de $\mathrm{KBr}$ da umidade, sendo que, antes e/ou após cada análise de uma amostra de gás, $\mathrm{o} \mathrm{N}_{2}$ também foi utilizado para fazer a limpeza do célula (gás de purga). A Figura 2 mostra uma foto da célula de gás confeccionada.

As medidas finais da célula de gás foram: comprimento do caminho óptico: 48,50 mm fixos; volume: $3,37 \mathrm{~mL}$; janelas: $\mathrm{KBr}$ (13 x 0,30 mm).

\section{Sistema de mangueiras e operação da célula}

Para a operação da célula foi montado um sistema constituído por mangueiras, conecções em T e válvulas por onde todos os gases foram 


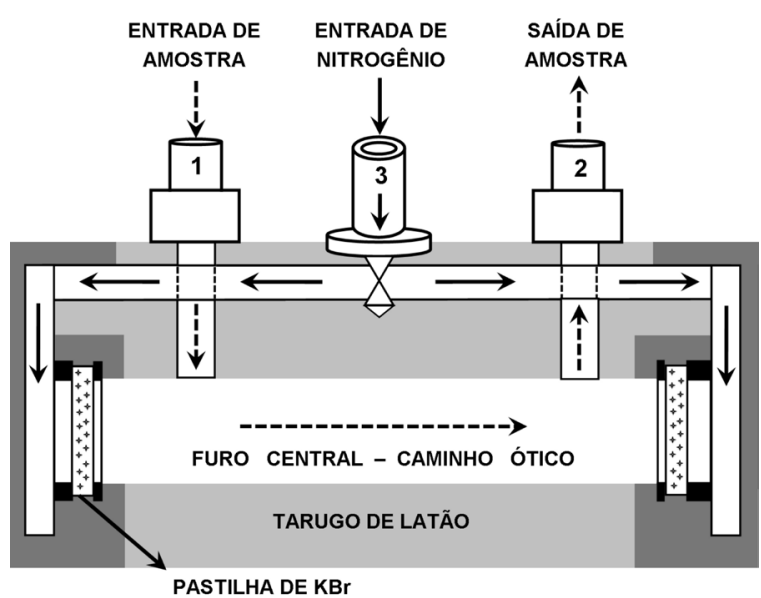

Figura 1. Esquema da célula de gás construída para análise no infravermelho. Os números 1 e 2 indicam os orifícios interligados e 3 o orifício isolado. As setas indicam o caminho percorrido pelos gases



Figura 2. Foto da célula de gás construída

introduzidos na célula, Figura 3. Por este sistema, pode-se controlar de forma independente, durante toda a análise, o fluxo constante de nitrogênio, que protege as janelas de $\mathrm{KBr}$, assim como, quando necessário, permitir o uso do $\mathrm{N}_{2}$ como gás de purga para limpeza da célula. A Figura 3 representa esquematicamente o sistema montado.

Para as análises das amostras de gases, confinados ou em fluxo e para a limpeza da célula, utilizaram-se os seguintes procedimentos descritos a seguir e representados na Figura 3.

Caso 1: Limpeza da célula - Gás presente: $\mathrm{N}_{2}$.

- Válvulas fechadas: a - c - e; - Válvulas abertas: b-d

- Caminho percorrido pelo $\mathrm{N}_{2}$ : D - 5 - C - 4 - B - 1 - célula - 2 - H

- 7 - G - 6 - F - 3 -janelas.

Caso 2: Análise de um gás - Gases presentes: $\mathrm{N}_{2}$ (protegendo as janelas de $\mathrm{KBr}$ ) e amostra.

- Válvulas fechadas: b - d; - Válvulas abertas: a - c-e

- Caminho percorrido pelo $\mathrm{N}_{2}$ : D - 5 - E - 6 - F- 3 - janelas.

- Caminho percorrido pela amostra: A - 4 - B - 1 - célula - 2 - H -

7 - I - ambiente.

Gases e espectrômetro utilizados

Os gases utilizados nos testes da eficiência da célula construída foram o GNV (gás natural veicular), acetileno (etino, $\mathrm{C}_{2} \mathrm{H}_{2}$ ) e gás carbônico $\left(\mathrm{CO}_{2}\right)$, todos de pureza industrial. Para realização das análises, os gases coletados diretamente de seus respectivos cilindros foram condicionados em bags. Antes do confinamento de cada gás,
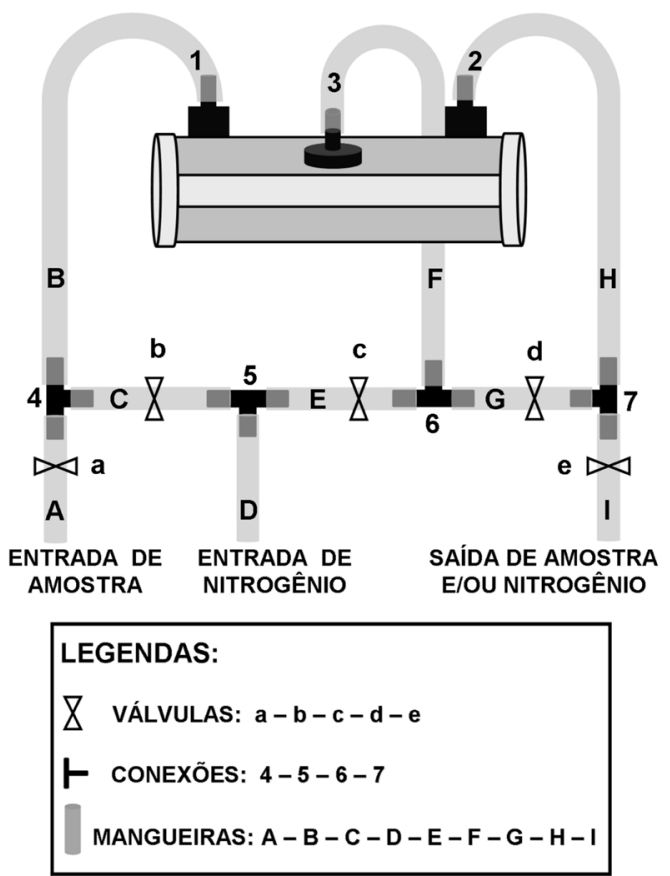

Figura 3. Esquema do sistema montado para operação da célula de gás

as bags foram cheias e esvaziadas, consecutivamente por três vezes, visando eliminar qualquer gás interferente.

Os espectros de infravermelho foram registrados em um espectrômetro Bomem, FT-IR-FTLA2000-102. As análises foram realizadas em um intervalo de número de onda de 4000 - $400 \mathrm{~cm}^{-1}$, com média de 16 varreduras e resolução de $4 \mathrm{~cm}^{-1}$.

\section{Avaliação dos espectros}

Para avaliação da qualidade do sinal espectroscópico gerado através da célula construída obtiveram-se os espectros pela seguinte sequência: limpeza da célula; realização de um branco; injeção de GNV; limpeza da célula; realização de um branco; injeção de acetileno; limpeza da célula; realização de um branco; injeção de $\mathrm{CO}_{2}$.

\section{Reprodutibilidade e eficiência da limpeza da célula para análises sequenciais}

Os três gases, GNV, $\mathrm{C}_{2} \mathrm{H}_{2}$ e $\mathrm{CO}_{2}$, foram utilizados para a verificação da reprodutibilidade do sinal espectroscópico e, também, da eficiência do sistema para a realização de análises sequenciais de diferentes amostras gasosas. $\mathrm{O}$ teste foi conduzido da seguinte forma: limpeza inicial da célula com $\mathrm{N}_{2}$ por $10 \mathrm{~min}$; realização de um branco; $4^{\circ}$ min: iniciou-se o fluxo de GNV; $9^{\circ}$ min: iniciou-se a purga com $\mathrm{N}_{2} ; 18^{\circ} \mathrm{min}$ : sem novo branco, iniciou-se o fluxo de $\mathrm{C}_{2} \mathrm{H}_{2} ; 32^{\circ} \mathrm{min}$ : iniciou-se nova purga com $\mathrm{N}_{2} ; 48^{\circ}$ min: sem novo branco, iniciou-se o fluxo de $\mathrm{CO}_{2} ; 60^{\circ}$ min: realizou-se a última purga com $\mathrm{N}_{2}$.

Durante todo o experimento de reprodutibilidade e eficiência da limpeza da célula para análises sequenciais, os espectros foram registrados em períodos de $1 \mathrm{em} 1 \mathrm{~min}$.

\section{RESULTADOS E DISCUSSÃO}

\section{Levantamento de custos}

A célula de gás construída apresentou um custo total de US\$ 85,63 , sendo US\$29,07 referentes aos materiais utilizados (tarugo 
de latão, conecções em T, mangueiras, anéis de vedação) e US\$ 56,56 aos custos de mão de obra (torneiro mecânico). Uma célula de gás com janelas de $\mathrm{KBr}$, equivalente à descrita neste trabalho, pode ser encontrada no mercado por um valor aproximado de US\$532,00, ${ }^{3}$ desconsiderando as taxas de importação, uma vez que acessórios deste tipo não estão disponíveis no mercado nacional. Pelos valores apresentados, a célula de gás construída para análise no infravermelho mostrou-se economicamente bastante atrativa e mais acessível que aquelas disponíveis atualmente no mercado. O processo de confecção da célula é relativamente simples e de fácil desempenho e os materiais necessários podem ser facilmente adquiridos em lojas de ferragem e de material de construção.

\section{Avaliação dos espectros}

A Figura 4 mostra os espectros obtidos para as análises do GNV, $\mathrm{C}_{2} \mathrm{H}_{2}$ e $\mathrm{CO}_{2}$ utilizando a célula construída.


Figura 4. Espectros de infravermelho obtidos com a célula de gás construída

O espectro do GNV (Figura 4 a) constituído dos hidrocarbonetos metano (em maior porcentagem), etano, propano e butano apresenta um espectro típico de hidrocarboneto saturado, observando-se a região de deformações axiais $\mathrm{C}-\mathrm{H}$ próximas de $3000 \mathrm{~cm}^{-1}$ e a região de deformações angulares $\mathrm{C}-\mathrm{H}$ próximas de $1300 \mathrm{~cm}^{-1}$. No espectro do $\mathrm{C}_{2} \mathrm{H}_{2}$ (Figura 4 b) é observado o dubleto em 3305 e $3269 \mathrm{~cm}^{-1}$, que corresponde à deformação axial de $\mathrm{C}-\mathrm{H}$ de alquinos, e a banda em $731 \mathrm{~cm}^{-1}$, correspondendo à deformação angular de $\mathrm{C}-\mathrm{H}$ do $\mathrm{C}_{2} \mathrm{H}_{2} \cdot{ }^{6}$
O espectro do $\mathrm{CO}_{2}$ (Figura 4 c) mostra absorções intensas em 2350 e $669 \mathrm{~cm}^{-1}$, referentes à deformação axial assimétrica e à deformação angular do $\mathrm{CO}_{2}$, respectivamente. ${ }^{6}$ Os espectros obtidos experimentalmente foram comparados com os da literatura e se apresentaram bastante satisfatórios. ${ }^{?}$

\section{Reprodutibilidade e eficiência de limpeza para análises sequenciais}

O procedimento empregado para a limpeza da célula apresentou boa resposta para a situação de análises sequenciais. Foi possível a troca de amostra de gás, sem que isto alterasse significativamente a leitura espectroscópica. A qualidade da linha base do sinal espectroscópico foi afetada apenas ao redor dos números de ondas 3353 e 1639 $\mathrm{cm}^{-1}$, regiões que correspondem a absorções da água. Uma vez que o $\mathrm{KBr}$ é higroscópico, o tempo que as pastilhas ficaram expostas antes do início da análise foi o suficiente para que ocorresse absorção de umidade do ambiente. Além disso, os gases de baixa pureza utilizados para as análises continham umidade, contribuindo para a observação relatada. Entretanto, como observado para as análises realizadas, essa pequena variação nos espectros registrados não se mostrou um interferente prejudicial à interpretação das bandas. Isso significa que as janelas de $\mathrm{KBr}$ ficaram, como planejado, satisfatoriamente protegidas da umidade pelo fluxo de nitrogênio durante todo o experimento.

É importante observar que os tempos gastos na limpeza da célula durante a análise sequencial variaram com o tipo de gás, gastando-se 3, 6 e 14 min para a completa remoção dos gases $\mathrm{GNV}, \mathrm{CO}_{2}$ e $\mathrm{C}_{2} \mathrm{H}_{2}$, respectivamente, do interior da célula. Estas diferenças, possivelmente, podem ser explicadas por meio da espontaneidade de adsorção física, que ocorre entre as amostras gasosas e o latão, material que constitui a célula.

Constatou-se também que o tempo necessário para detecção de amostra pelo espectrômetro foi o mesmo para todos os gases (1 min). Essa observação é compatível com o que foi descrito anteriormente, uma vez que para a amostra atingir o caminho óptico da célula, ela atravessa apenas uma pequena conexão de latão, a qual apresenta uma área consideravelmente menor que a célula de gás, ou seja, o tempo de contato entre os gases e esta estrutura, possivelmente, não é suficiente para que haja um processo de adsorção.

Um dos problemas encontrados no experimento foi a variação do fluxo de gás da bag para a célula, o que alterou com o passar do tempo a intensidade do sinal espectroscópico. Uma forma simples de solucionar esse problema seria controlar o fluxo de gás para a célula com um controlador de vazão.

A eficiente reprodutibilidade dos espectros, mostrados na Figura 4 , foi também observada quando os gases foram analisados individualmente.

\section{CONCLUSÕES}

Comparando-se o preço estimado da célula de gás modelo Short-Path HT Gas Cell, comercializada pela Pike Technologies (US\$532,00 + taxas de importação), equivalente à descrita neste trabalho, US\$85,63, conclui-se que o principal objetivo foi alcançado, ou seja, desenvolveu-se, a partir de materiais facilmente acessíveis e de baixo custo, uma célula de gás para análise no infravermelho mais acessível economicamente e satisfatoriamente adequada para análises qualitativas, já que os espectros obtidos com o dispositivo construído foram consistentes com os espectros da literatura, havendo ainda a reprodutibilidade dos resultados.

Foi comprovada também a possibilidade da célula ser utilizada em análises sequenciais, pois a sua limpeza, assim como a de todo o sistema, foi realizada em um curto espaço de tempo, sendo que este tempo variou dependendo do gás analisado. 
$\mathrm{O}$ fato das janelas de $\mathrm{KBr}$ serem sensíveis à umidade e do fluxo do gás da bag para a célula não ter sido constante não impediu que se obtivesse um excelente resultado espectroscópico para análises qualitativas.

\section{AGRADECIMENTOS}

Ao LabPetro/UFES, CNPq, Arcelormittal, Sr. D. Poltronieri.

\section{REFERÊNCIAS}

1. Xiaobo, Z.; Jiewen Z.; Povey, M. J. W.; Holmes, M.; Hanpin, M.; Anal. Chim. Acta 2010, 667, 14

2. Stuart, B. H.; Infrared Spectroscopy: Fundamentals and Applications, John Wiley \& Sons: Sydney, 2004.
3. http://www.piketech.com, acessada em Abril 2010 e Janeiro 2011.

4. http://www.ftir.com, acessada em Abril 2010 e Janeiro 2011.

5. Oliveira Jr., J. M.; Andréo Filho, N.; Chaud, M. V.; Gonçalves, M. M.; Aranha, N.; Lima Jr., J. R.; Quim. Nova 2010, 33, 1384; Alencar, M. A. S.; Benedetti, A. V.; Fugivara, C. S.; Messaddeq, Y.; Quim. Nova 2010, 33, 1394; Kamogawa, M. Y.; Teixeira, M. A.; Quim. Nova 2009, 32, 1644.

6. Silverstein, R. M.: Webster, F. X.: Kiemle, D. J.; Identificação Espectrométrica de Compostos Orgânicos, $7^{\mathrm{a}}$ ed., LTC: Rio de Janeiro, 2006.

7. http://webbook.nist.gov/chemistry, acessada em Abril 2010 e Janeiro 2011.

8. Atkins, P.: De Paula, J.; Físico-Química, 8a ed., LTC: Rio de Janeiro, 2006. 